\title{
Work-related conflict and nurses' role performance in a tertiary hospital in South-south Nigeria
}

\author{
Idongesit I. Akpabio ${ }^{* 1}$, Mildred E. John ${ }^{1}$, Margaret I. Akpan ${ }^{1}$, Felicia F. Akpabio ${ }^{2}$, David A. Uyanah ${ }^{3}$ \\ ${ }^{1}$ Department of Nursing Science, College of Medical Sciences, University of Calabar, Calabar, Cross River State, Nigeria \\ ${ }^{2}$ Continuing Education Unit, University of Calabar Teaching Hospital, Calabar, Cross River State, Nigeria \\ ${ }^{3}$ Department of Mathematics and Statistics, Cross River University of Technology, Calabar Campus, Calabar, Nigeria
}

Received: August 24, 2015

DOI: $10.5430 /$ jnep.v6n2p106
Accepted: October 25, $2015 \quad$ Online Published: November 9, 2015

URL: http://dx.doi.org/10.5430/jnep.v6n2p106

\begin{abstract}
Background: Work-related conflict (WRC) may be inevitable but can interfere with nurses' roles performance if not well managed. Nurses are unique in the directions from where conflicts emerge: administrators, nursing colleagues, physicians, Para-medical staff, patients and their families. Un-resolved conflicts may be linked to poor communication resulting from refusal to cooperate, poor team collaboration and problem-solving, decreased clients' satisfaction, distrust, split camps, gossips and disruption of work-flow. This study investigated sources of WRC and their influence on nurses' independent and inter-dependent roles in a Tertiary Hospital in South-south Nigeria.

Methods: A 50-items WRC questionnaire built on a four-point Likert-type scale was used to collect data from a random sample of 242 nurses of all ranks, representing $40 \%$ of the target population of 585. The instrument had internal consistency of $r=.81$ and test-retest reliability of $r=.83$. Data were analyzed using independent $t$-test determined at significance level of .05 .

Results: Results showed that female respondents were 237 (98\%) while $5(2 \%)$ were males. The major sources of WRC included: conflicts as a result of overwork and poor rewarding system each with frequency of 222 (92\%); patients-related conflict and leadership conflicts each with frequency of 218 (90\%); misunderstanding involving nursing colleagues with a frequency of 194 (81\%); poor work environment $192(80 \%)$; conflicts with other health professionals with 189 (78\%) frequency and discrimination issues with $180(61 \%)$ frequency. Furthermore, there was no significant influence of WRC on nurses' independent and inter-dependent roles. (Cal. $t=-4.6 ; P=.00$; Observed mean $=37.7<$ Expected mean $=40.0$ and Cal. $t=-9.3 ; P=.00$; Observed mean $=17.5<$ Expected mean $=20.0$ ).

Conclusions: Many sources of WRC were observed among the nurses but they were found to have no influence on their roles' performance probably due to the ethical and legal implications of nursing duties. Recommendations included effective and timely communication at all times among nurses, hospital administrators and other stake-holders.
\end{abstract}

Key Words: Hospital, Independent-roles, Inter-dependent roles, Nurses, Work-related conflict

\section{INTRODUCTION}

Conflict is one of many issues found in any organization including hospitals, where there are human interactions and especially in situations when the achievement of one's goals clashes with the achievement of another person's goals. ${ }^{[1]}$
Conflict is often a major issue when significant changes are made to strategic goals, objectives and plans. Such changes often require employees and other stakeholders to alter their goals, roles and attitudes as well as having flow or effects on organizational structure and culture.

\footnotetext{
*Correspondence: Idongesit I. Akpabio; Email: idongawa@yahoo.com; Address: Department of Nursing Science, College of Medical Sciences, University of Calabar, P.M.B.1115, Calabar, Cross River State, Nigeria.
} 
Nurses occupy a very strategic place in the hospital setting by virtue of their roles. They stay closest to the patients and their relatives. They contribute very important roles both in the achievement of hospital goals as well as the clients' satisfaction with care. For them to perform these roles effectively and efficiently there must be a strong cordial relationship not only between the nurses and their employers but also between them and other members of the health team as well as the patients and their relatives. As a result of these various human interactions, conflict in the hospital, which in many cases involves nurses, is inevitable. It is documented that conflicts include differences of opinion and perceptions at all levels of interaction including supervision, shared work and living spaces, teaching and learning. ${ }^{[2]}$ Conflicts can arise between co-workers, supervisors, team members and subordinates, or between employees and external stakeholders such as patients and relatives, suppliers and the regulatory agencies. This statement corroborates the fact that the potential for conflict to arise in a hospital setting is considerably higher due to the complex and frequent interactions among the nurses and other employees as well as the variety of roles they play. ${ }^{[3]}$ Specialization and organizational hierarchy often add to the territorial conflicts in hospitals. ${ }^{[4]}$

Although a reasonable amount of conflict in the form of competition can contribute to a higher level of performance, how conflict is addressed is of paramount importance. ${ }^{[5]}$ This assertion is in line with the opinion that conflict can be both functional (helpful) or dysfunctional (harmful) to a workplace. ${ }^{[6]}$ According to him, those who promote the pluralist and the interactional approaches to organizations believe that workplace conflict can act as potential source of energy, which if managed properly can be used to explore a wider range of problem-solving options than the old traditional approach. Their argument is that by bringing the issues out into the open and addressing them rather than hiding them, the opportunity exists to assess all sides to a situation and therefore increase the probability of finding the right solution. With the new approaches, conflict damaging potential is not ignored, unlike the traditional approach, which perceives conflict as undesirable situation that needed to be avoided and eliminated at all cost. The viewpoint therefore is that because of the inevitable and problem-solving potential, the emphasis should be on the need to develop management skills that can enable leaders to adopt a relevant approach to each conflict situation.

According to researchers functional conflict can turn into emotional conflict and crisis if not managed properly and this in turn can disrupt collaborative efforts, lead to unprofessional behaviours, under-commitment to the organization, increase psychological stress and emotional exhaustion, re-

Published by Sciedu Press sults in mistreatment of patients, elevate anxiety and work resignation and decrease altruistic behavior. ${ }^{[1]}$ To them, the aforementioned abnormal situations are only a few from a long list of negative consequences of poorly managed conflict. Conflict in the hospital sector, sometimes involving nurses oftentimes remain perennial and disturbing, so much that it has hampered the health care system in many instances. Sometimes, the conflict may be intra-personal within the individual while at other times it may be interpersonal between individuals or inter-group between groups. In each case, conflict consumes much of the time and attention that should otherwise be committed to provision of services. This development can largely occur due to inability of leaders as well as subordinates to view the management of conflict as systematically as they view information acquisition, human resources recruitment and financial management systems. ${ }^{[7]}$ Most often, conflict is observed as being handled piecemeal or as emergency action among individuals or groups when there is total breakdown of peace. The results are often strike action, unhealthy rivalry between and among sub-units and individuals in the hospital, sabotage at workplace, absenteeism, low morale, withholding of vital knowledge and or services and a host of other abnormal activities in the workplace. Workplace conflict when it becomes dysfunctional may affect performance of nurses' independent and interdependent roles. The first step for effective management of conflict among groups would be the recognition of conflict and its sources, and then understanding how to moderate and control them according to assessment results. ${ }^{[1]}$

Everyone has to deal with conflict both in the workplace and personal lives. Nurses are no exception. Nurses however are unique in the directions from where conflicts emerge: Administrators, nursing colleagues, doctors, Para-medical staff as well as patients and their families. It is also argued that the causes of conflict include competition, rumours, unclear responsibilities, lack of information or poor communication, leadership conflict or poor management, misunderstandings, unfair treatment, poor work environment, discrimination or lack of equal opportunities, bullying and harassment, hierarchy, inadequate training, budget or economic conflict as well as stubbornness or hurting of feelings, hidden agenda, empire building and breach of promise. ${ }^{[8]}$ In addition to aforementioned determinants of conflicts, Toolkit identified other sources to include values conflict and power conflict. ${ }^{[9]}$ It is important to note that the aforementioned causes of conflict can be grouped and discussed under communication, structural and personal problems. From whatever causes, unresolved conflict may be detrimental to organizational growth. This is rooted in the fact that conflict in the workplace is linked to poor communication resulting from confusion or 
refusal to cooperate, quality problems, missed datelines or delays, increased stress among employees, poor team collaboration and problem-solving, decreased clients' satisfaction, distrust, split camps, gossips and disruption of workflow. ${ }^{[10]}$

Considering the crucial nature of nurses' jobs, these anomalies may seriously hinder the performance of their independent and inter-dependent roles. Furthermore, it is assumed that inter-personal conflict among people at work has been shown to be one of the most frequently noted stressors for employees. ${ }^{[11]}$ Similarly, many authors have observed that conflict can be an indicator of the broader concept of workplace harassment relating to other stressors that might cooccur, such as role conflict, role ambiguity and workload. ${ }^{[12]}$ It may therefore be argued that these are all pointers towards inefficiency in role performance be it independent or interdependent roles.

It should therefore be assumed that once the conflict and its sources are identified, addressing the conflict can be instrumental in enhancing professional development and reducing the burnout rate among nurses. These therefore provide impetus for this study. Many authors have investigated the influence of stress on job satisfaction and roles performance among nurses but there is dearth of information on the sources of work-related conflict prevalent among nurses, and the influence of work-related conflict on nurses' performance of independent and inter-dependent roles. Against this background, this study was therefore aimed at investigating:

(1) The sources of work-related conflict prevalent among nurses in the study area;

(2) The influence of work-related conflict on the performance of nurses' independent roles;

(3) The influence of work-related conflict on the performance of nurses' inter-dependent roles.

Two null hypotheses were generated for testing and these were as follows:

(1) There will be no significant influence of work-relatedconflicts on nurses' performance of independent roles;

(2) There will be no significant influence of work-related conflicts on nurses' performance of inter-dependent roles.

\section{MATERIALS AND METHODS}

The study involved a descriptive survey design to study the influence of work-related conflict on nurses' role performance in a Tertiary institution in South-south Nigeria. The hospital is a referral centre for all the health care services. It is also concerned with training of medical and Para-medical staff.

\subsection{Population and sampling technique}

The target population covered a total of five hundred and eighty-five nurses in all the sections of the hospital. From this number, proportionate stratified random sampling method of balloting with replacement was carried out to select 242 nurses of different ranks, representing $40 \%$ of the target population from six sections of the hospital. To do this, a list of nominal roll of all the nurses of different ranks in the various wards and units was obtained from the nursing administration department of the hospital. From this list, a number representing $40 \%$ from each of the ranks was selected. This was done through assistance of three trained research assistants who drew the "yes" or "no" folded papers from containers. The first group of nurses who had "yes" picked against their names were selected until the predetermined number from each rank was selected. Where it was difficult to access a subject, balloting was again done for a replacement until the predetermined number from each rank was obtained. There was no limitation on the inclusion criterion. All the nurses had equal opportunity of being selected.

\subsection{Instrument for data collection}

The instrument for data collection was the 50-item Workrelated Conflict Assessment Questionnaire constructed by the researchers. The questionnaire had four sections. Section A with eight items was for collection of socio-demographic data of respondents, section B elicited data on work-related conflict prevalent among nurses in the Hospital, and Section $\mathrm{C}$ was concerned with influence of work-related conflict on the performance of nurses' independent roles while section D provided information on the influence of work-related conflict on performance of nurses' inter-dependent roles. Apart from, the section on socio-demographic data of respondents, the other items were built on Likert scale, with responses ranging from strongly agree to Agree, Disagree and strongly disagree. For each of the items, the respondents were expected to choose the option that best fitted their opinions. The items were vetted by two experts in measurement and two senior academics in nursing. The computed content validity index (CVI) of .89 was obtained. The internal consistency was measured with Cronbach Alpha for the three sub-scales with results recorded as $.93, .87$ and .94 for work-related conflicts, its influence on the performance of independent and on inter-dependent roles respectively. For sections B, C and $\mathrm{D}$, the scoring from the instrument was done such that positively worded statements attracted higher scores indicating conflicts. Thus responses of strongly agree (SA) was awarded four (4) points, Agree (A) 3 points, Disagree (D) 2 points and Strongly Disagree (SD) one point. The scoring were reversed for negatively worded items. 


\subsection{Ethical consideration}

Written permission was obtained from the Ethical Committee of University of Calabar Teaching Hospital to carry out the study in the hospital among the nurses. The researchers also obtained informed consent from the respondents. All information obtained during the study was kept confidential and only used for the purpose of the research. Anonymity of respondents was maintained for confidentiality as they were not expected to write their names on any part of the questionnaire. No part of the research procedure was expected to pose a source of physical or emotional harm to the respondents.

\subsection{Data collection}

The data were collected by the researchers and three trained research assistants on a face-to face interaction with the respondents in their wards units or offices. The completed questionnaires were retrieved immediately or on the same day after the period of their break and this ensured hundred percent return rate. The data collection lasted for a period of two weeks.

\subsection{Procedure for data analysis}

The scores were added separately for each sub-scale. The resulting data were analyzed using Statistical Package for
Social Sciences (SPSS) Version 18.0, using descriptive statistics of means and standard deviations and One-way Analysis of Variance (ANOVA) and Population $t$-test to test the stated hypotheses at .05 significant levels. The mean and Standard Deviations of the three dependent variables: Work-related conflicts; its influence on nurses' independent roles and on inter-dependent roles were computed. The observed mean values were tested for significance against their corresponding expected (population) means using the population $t$-test. The results are presented in Tables 1-3.

\section{RESULTS}

Results were organized based on the study objectives and hypotheses.

Table 1 shows that 237 (98\%) of the respondents were females and $5(2 \%)$ were males. Majority 69 (29\%) were Nursing officers 11 followed by chief nursing officers (CNO) with 67 (28\%) respondents. Regarding their age, majority 93 (38\%) were aged 25-35 years followed by age group 46-55 years with $74(31 \%)$ respondents. For highest professional qualifications, majority 189 (78\%) had Registered Nurse/Registered Midwife certificates.

Table 1. Socio-demographic data of respondents $(n=242)$

\begin{tabular}{|c|c|c|}
\hline Variables & Frequency & Percentage (\%) \\
\hline \multicolumn{3}{|l|}{ Gender } \\
\hline Males & 5 & 2 \\
\hline Females & 237 & 98 \\
\hline Total & 242 & 100 \\
\hline \multicolumn{3}{|l|}{ Age in years } \\
\hline 25-35 & 93 & 38 \\
\hline $36-45$ & 69 & 29 \\
\hline $46-55$ & 74 & 31 \\
\hline $56-60$ & 6 & 2 \\
\hline Total & 242 & 100 \\
\hline \multicolumn{3}{|l|}{ Prof. ranks } \\
\hline Nursing Officers 1 (NO 1) & 44 & 18 \\
\hline Nursing Officers 11 (NO 11) & 69 & 29 \\
\hline Senior Nursing Officers (SNO) & 29 & 12 \\
\hline Principal Nursing Officers (PNO) & 7 & 3 \\
\hline Asst. Chief Nursing Officer (ACNO) & 23 & 10 \\
\hline Chief Nursing Officers (CNO) & 67 & 28 \\
\hline Assistant Directors (AD) & 3 & 1 \\
\hline Total & 242 & 100 \\
\hline \multicolumn{3}{|l|}{ Prof. qualification } \\
\hline Reg. Nurses/Midwives(RN/RM) & 189 & 78 \\
\hline B.Sc/B.N.Sc. & 45 & 19 \\
\hline M.Sc. & 8 & 3 \\
\hline Total & 242 & 100 \\
\hline
\end{tabular}


Results of the sources of work-related conflict prevalent among nurses in the study setting as presented in Table 2 show that the most common sources of work-related conflicts are conflicts due to over-work and poor rewarding system with a frequency of $222(92 \%)$. The next most common sources are leadership conflicts involving personality clashes between nurse leaders and their subordinates and patientrelated-conflicts with $218(90 \%)$ frequency. The third highest source of conflict is intra-personal conflicts involving nursing colleagues with $194(81 \%)$ frequency, followed by poor work environment with 192 (80\%) frequency. The least sources of work-related conflicts were seen in unclear job responsi- bilities with a frequency of 26; conflict of values as well as rumours with $24(10 \%)$ frequency. Unclear responsibilities or job roles accounted for 26 (11\%) frequency.

\section{Results from hypotheses}

Ho1: There will be no significant influence of work-related conflict on the performance of nurses' independent roles.

Ho2: There will be no significant influence of work-related conflicts on the performance of nurses' inter-dependent roles.

The results from the two hypotheses are presented in Table 3 .

Table 2. Sources of work-related conflict prevalent among nurses $(n=242)$

\begin{tabular}{|c|c|c|c|c|}
\hline Items & SA & $\mathbf{A}$ & $\mathbf{D}$ & SD \\
\hline Conflict as a result of overwork & $116(48 \%)$ & $106(44 \%)$ & $5(2 \%)$ & $15(6 \%)$ \\
\hline Poor rewarding system & $174(72 \%)$ & $48(20 \%)$ & $5(2 \%)$ & $15(6 \%)$ \\
\hline Patient-related-conflict & $194(80 \%)$ & $24(10 \%)$ & $5(2 \%)$ & $19(8 \%)$ \\
\hline $\begin{array}{l}\text { Leadership conflict/Personality clashes between nurse leaders and } \\
\text { subordinates }\end{array}$ & $182(75 \%)$ & $36(15 \%)$ & $17(7 \%)$ & $7(3 \%)$ \\
\hline $\begin{array}{l}\text { Intra-personal conflict or misunderstanding involving nursing } \\
\text { colleagues }\end{array}$ & $121(51 \%)$ & $73(30 \%)$ & $27(11 \%)$ & $19(8 \%)$ \\
\hline Poor work environment & $116(48 \%)$ & $76(32 \%)$ & $22(9 \%)$ & $28(12 \%)$ \\
\hline $\begin{array}{l}\text { Inter-group conflicts between nurses and other healthcare } \\
\text { professionals }\end{array}$ & $145(60 \%)$ & $44(18 \%)$ & $24(10 \%)$ & $29(12 \%)$ \\
\hline Discrimination issues & $34(41 \%)$ & $48(20 \%)$ & $48(20 \%)$ & $50(19 \%)$ \\
\hline Competition to attain scarce resources & $77(32 \%)$ & $85(35 \%)$ & $31(13 \%)$ & $48(20 \%)$ \\
\hline $\begin{array}{l}\text { Power conflicts with each party maximizing the amount of influence } \\
\text { that it exerts on another }\end{array}$ & $63(26 \%)$ & $73(30 \%)$ & $77(32 \%)$ & $29(12 \%)$ \\
\hline $\begin{array}{l}\text { Organizational conflict with inequalities among the groups in } \\
\text { organizational hierarchy }\end{array}$ & $63(26 \%)$ & $68(28 \%)$ & $58(24 \%)$ & $53(22 \%)$ \\
\hline Poor employer/employee relationship & $63(26 \%)$ & $68(28 \%)$ & $58(24 \%)$ & $53(22 \%)$ \\
\hline Poor communication and lack of information & $75(31 \%)$ & $56(23 \%)$ & $48(20 \%)$ & $63(26 \%)$ \\
\hline Poor management style and practice & $58(24 \%)$ & $53(22 \%)$ & $68(28 \%)$ & $63(26 \%)$ \\
\hline Unclear responsibilities or job roles & $19(8 \%)$ & $7(3 \%)$ & $50(19 \%)$ & $169(70 \%)$ \\
\hline Conflict of values & $17(7 \%)$ & $7(3 \%)$ & $73(30 \%)$ & 145 (60\%) \\
\hline Rumour & $19(8 \%)$ & $5(2 \%)$ & 73 (30\%) & 145 (60\%) \\
\hline
\end{tabular}

Table 3. Population $t$-test of observed against expected means for work-related conflict

\begin{tabular}{|c|c|c|c|c|c|}
\hline \multirow{2}{*}{ Variable } & \multicolumn{2}{|c|}{ Observed } & \multirow{2}{*}{$\begin{array}{l}\text { Expected } \\
\text { Mean }\end{array}$} & \multirow{2}{*}{$t$-value } & \multirow{2}{*}{$P$-value } \\
\hline & Mean & SD & & & \\
\hline Work-related conflict (WRC) & 54.6 & 7.7 & 47.5 & $14.3^{*}$ & .000 \\
\hline WRC \& Independent roles & 37.7 & 7.7 & 40.0 & $-4.6^{*}$ & .000 \\
\hline WRC \& Inter-dependent roles & 17.5 & 4.3 & 20.0 & $-9.3 *$ & .000 \\
\hline
\end{tabular}

*Significant at .05 level; $P<.05 ; \mathrm{df}=241$

Regarding the influence of work-related conflict on the per- related conflicts, its influence on nurses' independent roles formance of nurses' independent roles, the mean and stan- were computed. The observed mean values were tested for dard deviations of the dependent variables including work- significance against their corresponding expected (Popula- 
tion) means using the Population $t$-test. Results on Table 3 show that the influence of WRC on nurses' performance of independent roles was significant $(P=.000)$. However, the observed mean of work-related conflict (37.7) is lower than expected mean (40.0) with $t$-value also negative (-4.58). (Cal. $t=-4.6 ; P=.00 ;$ Observed mean $=37.7<$ Expected mean $=40.0$ ). This means that the influence of WRC on nurses' performance of independent roles is significantly lower than expected. Thus, the level of performance of independent roles is still higher than what should have been expected for the level of conflicts experienced.

In the case of hypothesis two, the result showed that the influence of WRC on nurses' performance of inter-dependent roles was significant $(P=.000)$. Similarly, the observed mean of WRC on inter-dependent roles (17.5) is also lower than the expected mean (20.0) (Cal. $t=-9.3 ; P=.00$; Observed mean $=17.5<$ Expected mean $=20.0)$. Thus, the level of performance of inter-dependent roles is still higher than what should have been expected for the level of conflicts experienced.

\section{Discussion}

This paper is a report of a study conducted to determine the types or common sources of WRC prevalent among nurses in their work environment and to describe the influence of conflict on the performance of their independent and interdependent roles. We observed major sources of WRC with percentage scores, which ranged from $55 \%$ to $92 \%$ and some minor sources of conflict with percentages, which ranged from $10 \%$ to $49 \%$.

The major sources of WRC in order of higher to lower ranking were: (1) Conflicts as a result of over-work and poor rewarding system; (2) Patient related and Leadership conflicts involving personality clashes between nurse leaders and subordinates; (3) Intra-personal or misunderstanding with nursing colleagues; (4) Poor work environment; (5) Inter-group conflict between nurses and other healthcare professionals; (6) Discrimination issues; (7) Competition to attain scarce resources; (8) Power conflict with each party maximizing influence over another; (9) Intra-personal conflict involving nursing colleagues; (10) Poor communication or lack of adequate and timely information; poor employer/employee relationship and other organizational conflicts. The minor levels of work-related conflicts included: poor management styles and practice; unclear responsibilities or job roles; spreading of rumour and conflicts of values. On the other hand, further results showed that the existence of aforementioned sources did not have significant high level of influence on the performance of independent and inter-dependent roles among the nurses as would have been expected.
In line with the findings of this study, available literature globally has shown that conflict is an inevitable part of an organization and human relationships including hospital. ${ }^{[1]}$ However, the potential for conflict to arise in a hospital setting is considerably higher due to the complex and frequent interactions among the nurses and other employees, and the variety of roles they play. Furthermore, nurses occupy a very strategic position in the hospital setting by virtue of their roles. They stay closest to the patients and their families and therefore act as intermediaries between other hospital staff, patients and their relatives. Although a reasonable amount of conflict in any organization is said to be functional and can contribute to a higher level of performance since a conflictfree work environment is an exception, how conflict is addressed is of paramount importance. ${ }^{[5]}$ Researchers believe that functional conflict can turn into emotional conflict if not managed properly, and this in turn disrupts hospital functions within and between the various groups of hospital staff.

These sources of conflict observed in this study are similarly documented in literature as usually occurring when two people or more have incompatible needs, goals or approaches in their relationships, such as different communication or work styles. ${ }^{[13]}$ It should therefore be necessary to often address the situations objectively, directly and respectfully for each group without any unhealthy delay. This is necessary because these types of conflicts if not well managed can result in deadlock in negotiations with the negative consequences including: Grievance disputes, unfair labour practice and recognition disputes. Grievance disputes are those that arise from day-to-day grievances; unfair labour practices are disputes that arise from acts of interference with the exercise of rights to organize acts; and recognition disputes arise due to non-recognition of Trade Union as a bargaining agent.

The other sources of WRC were patient-related conflicts and poor work environment. With patient-related conflict, Johnston opined that oftentimes, interaction with patients and families comes at times when those they are attempting to care for are at their worst. ${ }^{[14]}$ This setting is ripe for workplace conflict. Nurses are expected to respond at the press of a button. They seem to possess the ability to comfort, educate and to treat. However, it is not uncommon for the anger, frustration and fear felt by the patients and families to be triggered by and targeted towards nurses. This is especially true when they are unable to remove the discomfort (Physical or emotional) experienced by those in the position. This argument corroborates with the opinion that patients have some expectations from nurses but on the other hand do not understand that most of such expectations do not fall under nursing duties. ${ }^{[1]}$ It therefore calls for targeted conflict management and communication training not only to assist 
nurses in their response to the non-medical needs of their patients but also directed towards the patients, clients and their families.

With poor work environment, available study as documented in literature showed that the nature and conditions of the job, the teaching atmosphere and the structure of the hospital management style and individual characteristics were associated with WRC. ${ }^{[1]}$ The findings of this study, which also included organizational conflict involving inequalities in the organizational chart, remuneration and reward system, power conflict when each party wishes to maintain or maximize the amount of influence that it exerts on another including the decision- making process are all similar to the sources of conflicts observed by Nayeri and Negarandeh. ${ }^{[1]}$

Other authors observed that conflict increases with the number of levels in organizational hierarchy. ${ }^{[4]}$ The consequences of the work environment conflict includes when employees work in very crowded settings with scarce working equipment and materials as well as poorly defined hierarchy relationships. When these occur, their interactions with patients, colleagues and leaders increase and potentially lead to stress, exhaustion, conflict and high turnover. ${ }^{[3]}$ Further argument is that conflict due to poor work conditions can induce nurses to resort to routine task performance, thus negatively affecting healthcare ${ }^{[4]}$ Conflict which occurs as a result of over-work as shown in this study confirms the assertion that overloading can lead to conflicts for most individuals. ${ }^{[15]}$ With this situation, it is suggested that one important strategy in reduction of such conflict should be a balanced nurse-patient ratio and clear task descriptions. ${ }^{[16]}$

The findings implicating economic conflict of budget and competition to attain scarce resources especially as it relates to differential salaries among various groups of hospital staff as observed in this study is very crucial. This situation often leads to a situation where the aggrieved parties or groups of professionals resort to industrial action to press on their grievances. Sometimes, attempts are made to prevent challenges and suppress conflict by force and coercion, thus aggravating already existing conflict. This statement is in line with the opinion expressed by Nelson and Cox when they condemned the use of coercion in conflict control. ${ }^{[16]}$ Many authors have identified and suggested more appropriate measures for conflict control. The findings from a qualitative study on the measures for the control of organizational conflicts showed that mutual understanding and interaction was found to be the most frequent and important category, comprising different aspects such as mutual understanding between colleagues, managers, personnel, patients and their relatives. ${ }^{[1]}$ Similarly, it was observed that conflict can be controlled through interactions and effective communication within and among groups in an organization. ${ }^{[16]}$ They also asserted that conflict arises because of misinformation or misunderstanding. Inadequate communication between nurses and co-workers can lead to conflicts and it is therefore asserted that good personnel inter-relationships and a higher level of understanding of others are negatively correlated with within-group conflict and can function as buffers. ${ }^{[17]}$

It was also observed in this study that there was significant influence of WRC on nurses' performance of independent and inter-dependent roles. However, the levels of performance of independent and inter-dependent roles were still higher than what should have been expected for the levels of conflicts experienced. The explanation for that can be deduced from the fact that many nurses whether as individuals or professional groups are conscious of their ethical and legal obligations to their patients and clients and can therefore do everything within their powers to maintain expected standards irrespective of negative prevailing circumstances. This argument confirms the explanation that since nursing is a humanistic profession; conflict may not affect nursing care rendered to patients in the course of nurses' duties. ${ }^{[17]}$ However, we conclude that it should still be expected that individuals can be at their best when motivated to work in a more conducive and environment friendly workplace.

\section{Conclusion}

This study identified many sources of WRC prevalent among nurses. The findings will provide a means for making recommendations for control measures. The sources of WRC among the study subjects from the highest to the least included:

(1) Conflicts as results of overwork and poor rewarding system;

(2) Patients' related and leadership conflicts;

(3) Intrapersonal conflict/misunderstanding among nursing colleagues;

(4) Poor work environment;

(5) Intergroup conflict between nurses and other health professionals;

(6) Discrimination issues;

(7) Competition to attain scarce resources;

(8) Political or power conflicts;

(9) Organizational conflict, poor employer/employee relationship, and poor communication;

(10) Unclear responsibilities or job roles;

(11) Conflicts of values and rumour.

The aforementioned conflicts are capable of having far reaching consequences on healthcare system and this may con- 
tribute to incessant strike actions and closure of facilities in the institution. The implication is usually lack of access to healthcare services especially for the vulnerable groups with accompanying negative impact especially with regards to the achievement of health related millennium development goals.

\section{Recommendations}

Based on the results of this study, and in line with available literature reflected in this work, the following are recommended:

(1) Proactive conflict management policies should be put in place by employers based on input from nurse representatives and other stakeholders in the institution so that they can always anticipate and respond to economic changes that can affect the welfare of nurses.

(2) There should always be systems put in place to promote effective and timely communication in the institution within and between groups.

(3) Hospital administrators should at all times maintain acceptable balance of nurse-patient ratios with clearly defined tasks for each group of workers to ease workoverload and burn-out.

(4) There is need for a targeted conflict management and communication training not only for nurses to assist their response to non-medical needs of their patients but also directed towards the patients and their relatives to enhance their understanding of their care expectations. This can include a brief explanation to the patients and their relatives during admission into the hospital, of the roles for each group of the hospital worker so as to prevent patients' expectation from nurses of roles that do not fall within nursing duties.

(5) The limitation of this study is that it did not focus at- tention on the influence of WRC generally on achievement of hospital goals and which can contribute to the incessant strike actions and closure of facilities. The implication is usually lack of access to healthcare services especially for the vulnerable groups who need care, and this can have negative impact with regards to achievement of health-related millennium development goals. Further research are therefore needed to determine the influence of WRC generally on achievement of the institution's goals and also to explore practical conflict management strategies that can apply based on the prevailing environmental circumstances in the clinical setting.

Since this study has shown the existence of very high levels of work-related conflicts among the study participants, we strongly believe it is necessary to implement the recommendations made so as to provide a more conducive environment for nursing care. This should consequently be of immense benefit to the quality of nursing care rendered; patients' satisfaction with the care; the growth of nursing profession and the healthcare system as a whole.

\section{ACKNOWLEDGEMENTS}

We acknowledge with thanks all the nurses and nursing administrators who provided data for this study. We also extend our gratitude to the Ethical Committee of the University of Calabar Teaching Hospital for approving our request and giving permission, which allowed us to conduct this research We are also very grateful to the numerous authors whose documented work were used as literature for this study.

\section{CONFLicts OF INTEREST Disclosure}

We declare that we have no competing interests.

\section{REFERENCES}

[1] Nayeri ND, Negarandeh R. Conflict among Iranian hospital nurses: A qualitative Study. Human Resources for Health. 2009; 7: 25. PMid:19302706 http://dx.doi.org/10.1186/1478-449 1-7-25

[2] University of Iowa. Conflict management at Iowa. 2010.

[3] Yu Z, Davidhizar R. Conflict management styles of Asian and Asian America Nurses: Implications for the nurse manager. The Health Care. 2010; 23: 46-53.

[4] Swansburg RC, Swansburg RJ. Introduction to Management and leadership for nurse managers (3rd ed.). Boston: Jones and Bartlett Publishers; 2002. PMid:12463564

[5] Tomy AM. Guide to nursing management and leadership (3rd. ed.). St. Louis: Mosby Company; 2006. Available from: http: //www.human-resources-health.com/7/1/25

Published by Sciedu Press
[6] Thomas KW. Organizational conflict, In S. K. Organizational behavior. 2006.

[7] Olakitan OO. An examination of some determinants of industrial conflict in employee-employer relationship. 2011.

[8] Royal G. Conflict is a fact of life in the workplace. 2011.

[9] Toolkit HR. Workplaces that work, conflict at work. 2014.

[10] Moriarty M. Workplace coach: Companies pay the price when managers avoid dealing with conflict. Seattlepi, In: Workplace conflict. 2007.

[11] Liu C, Spector PE. Cross-national job stress: A qualitative and quantitative study. Journal of Organizational Behaviour. 2007; 28(2): 209 239. http://dx.doi.org/10.1002/job.435

[12] Bowling NA, Beehr TA. Workplace harassment from the victim's perspective: A theoretical model and meta-analysis. Journal of Ap- 
plied Psychology. 2006; 91(5): 998-101. PMid:16953764 http: //dx.doi.org/10.1037/0021-9010.91.5.998

[13] Thomas-Kilmann E. Technical brief for the Thomas-Kilmann conflict mode. 2015. Available from: http://www.psychometrics.com/ docs/tki\%20technical\%20brief.pdf

[14] Johnston E. Staff nurses and workplace conflict. 2012. Available from: http://www. humanresources-health.com/content

[15] Tabler LM. Conflict and burnout in home healthcare as related to care giving models. Ph.D Thesis. Pittsburgh University, School of
Social Work. 2014

[16] Nelson HW, Cox DM. The causes and consequences of conflict and violence in nursing homes: Working toward a collaborative work culture. The Healthcare Manager. 2004; 23: 85-96. http: //dx.doi.org/10.1097/00126450-200401000-00014

[17] Cox KB. The effects of unit morale and inter-personal relations on conflict in the nursing unit. Journal of Advanced Nursing. 2001; 35: 17-25. PMid:11442678 http://dx.doi.org/10.1046/j.1 $365-2648.2001 .01819 . \mathrm{x}$ 